DOI: $10.5216 /$ cab.v14i4.19491

\title{
PRODUÇÃO, CARACTERIZAÇÃO E AVALIAÇÃO DE ENZIMAS FIBROLÍTICAS NA DIGESTIBILIDADE DA FORRAGEM DE MILHO
}

\author{
CRistine dos SANTOS SetTimi CYSNeiros ${ }^{1}$, Reginaldo NASSAR FerReira ${ }^{2}$, Michelly Ayres \\ OLIVEIRA ${ }^{3}$, ADRIANO OLIVEIRA FAVORETTO ${ }^{3}$, EMMANUEL ARNHOLD ${ }^{4}$, CIRANO JOSÉ ULHOA ${ }^{2}$ \\ 1Colaboradora Doutora do Instituto de Ciências Biológicas da Universidade Federal de Goiás, Goiânia, GO, \\ Brasil - cysneiroscristine@ hotmail.com \\ 2Professores Doutores do Instituto de Ciências Biológicas da Universidade Federal de Goiás, Goiânia, GO, Brasil \\ 3Graduandos da Escola de Veterinária e Zootecnia da Universidade Federal de Goiás, Goiânia, GO, Brasil \\ 4 Professor Doutor da Escola de Veterinária e Zootecnia da Universidade Federal de Goiás, Goiânia, GO, Brasil
}

Os objetivos deste trabalho foram os de produzir e caracterizar um complexo enzimático (CE) de Humicola grisea e avaliar seu efeito na digestibilidade verdadeira da matéria seca de forragem de milho. Observou-se que o fungo produziu as enzimas celulases, xilanase e $\beta$ glicosidase. A caracterização bioquímica mostrou que a celulase e xilanase produzidas apresentaram maior atividade a $50^{\circ} \mathrm{C}$. A temperatura ótima de $\beta$-glicosidase ficou entre 50 e $60^{\circ} \mathrm{C}$. $\mathrm{O}$ pH ótimo de celulase e xilanase foi 6,0 . Quanto à $\beta$-glicosidase, a enzima revelou maior atividade em pH 6,5. A celulase permaneceu estável após incubação por 60 minutos, a $39^{\circ} \mathrm{C}$. As xilanase e $\beta$ - glicosidase produzidas mantiveram 99,2 e 88,2\% de sua atividade, a $50^{\circ} \mathrm{C}$, durante 240 minutos, respectivamente. Os tratamentos foram: controle $(10 \mathrm{~mL}$ de água esterilizada); nível 1 (2,5 $\mathrm{mL}$ do CE); nível 2 (5,0 $\mathrm{mL}$ do $\mathrm{CE}) \mathrm{e}$ nível $3(10 \mathrm{~mL}$ do $\mathrm{CE})$. No ensaio de digestibilidade, verificou-se interação entre níveis enzimáticos e períodos de incubação no rúmen. Para 12; 24; 48 e 96 horas de incubação, $10 \mathrm{~mL}$ do CE aumentou a digestibilidade em 10,58; 12,52; 9,05 e 6,81\%, em relação ao controle. O fungo Humicolagrisea é produtor de enzimas de interesse na alimentação de ruminantes.

PALAVRAS-CHAVE:Ankom; bovino; celulase; fungo; xilanase..

\section{PRODUCTION, CHARACTERIZATION AND EVALUATION OF FIBROLYTIC ENZYMES ON DIGESTIBILITY OF FORAGE MAIZE}

\section{ABSTRACT}

The objectives of this research were to produce and characterize an enzyme complex (EC), using the fungus Humicola grisea, and evaluate its effect on true digestibility of forage maize dry matter. We observed that the fungus produced cellulase, $\beta$-glucosidase and xylanase enzymes. The cellulase and xylanase activities were high at the temperature of $50^{\circ} \mathrm{C}$. The optimum temperature of $\beta$-glucosidase was between 50 and $60^{\circ} \mathrm{C}$. The optimum $\mathrm{pH}$ of cellulase and xylanase enzyme was 6.0. As for $\beta$ glucosidase, the enzyme showed higher activity at $\mathrm{pH} 6.5$. Cellulase remained stable for 60 minutes at $39^{\circ} \mathrm{C}$. Xylanase and $\beta$-glucosidase maintained 99.2 and $88.2 \%$ of their activity at $50^{\circ} \mathrm{C}$ for 240 minutes, respectively. The treatments were as follows: control $(10 \mathrm{~mL}$ of sterile water), level 1 ( $2.5 \mathrm{~mL}$ EC), level 2 (5.0 mL EC) and level $3(10 \mathrm{~mL} \mathrm{EC})$. In the digestibility experiment, there was interaction between enzyme levels and time of incubation in the rumen. The addition of $10 \mathrm{~mL}$ of the fibrolytic enzymes improved the digestibility at $10.58 ; 12.52 ; 9.05$ and $6.81 \%$ compared to control for $12 ; 24 ; 48$ and 96 hours of incubation, respectively. The fungus Humicola grisea is an enzyme producer that is important in ruminant feed.

KEYWORDS: Ankom; bovine; cellulose; fungi; xylanase. 


\section{INTRODUÇÃO}

Os ruminantes possuem um ecossistema diverso e sofisticadode utilização dos carboidratos fibrosos da parede celular dos vegetais, graças à relação simbiótica com a população microbiana diversificada do rúmen.

Ainda que os microrganismos do rúmen consigam digerir celulose e outros carboidratos fibrosos, fatores relacionados à estrutura e composição da planta, como as interações físicoquímicas entre a matriz de hemicelulose e lignina, e os aspectos relacionados ao animal, como mastigação, salivação e pH ruminal, podem limitar a digestão do alimento no rúmen (MARTINS et al., 2006), o que leva à necessidade de novos programas biotecnológicos de alimentação animal para maximizar a utilização dos nutrientes.

O uso de enzimas fibrolíticas, produzidas por culturas de fungos filamentosos, na alimentação de ruminantes tem mostrado resultados satisfatórios, com aumento na digestibilidade da matéria seca e da fibra em detergente neutro, na produção de leite e no teor de gordura do leite (SCHINGOETHE et al., 1999), assim como no ganho de peso em bovinos (BEAUCHEMIN et al., 1995).

Ainda que as enzimas sejam catalisadores eficientes em sistemas biológicos, sua atividade é influenciada por fatores como pré-tratamento do alimento, $\mathrm{pH}$ e comprimento do trato gastrointestinal, grau de hidratação e temperatura do corpo do animal, susceptibilidade das enzimas exógenas ao ataque das enzimas endógenas, concentração do produto em razão da hidrólise enzimática, concentração da enzima endógena e tipo de ingrediente utilizado na dieta (ACAMOVIC \& MCCLEARY 1996).

Pesquisas mostram que não é possível estimar, somente com base na caracterização bioquímica, o potencial de enzimas exógenas em melhorar a utilização de uma dieta pelo animal. Consequentemente, ensaios in vitro são utilizados para avaliar a eficiência de diferentes grupos de enzimas na digestibilidade de dietas fornecidas a ruminantes (COLOMBATTO et al., 2003).

Este trabalho foi realizado com o objetivo de produzir e caracterizar um complexo de enzimas fibrolíticas, utilizando-se $\mathrm{o}$ fungo Humicola grisea,e avaliar seu efeito na digestibilidade da matéria seca da forragem de milho.

\section{MATERIAL E MÉTODOS}

Os experimentos foram conduzidos nos Laboratórios de Enzimologia e de Fisiologia da Digestão do Instituto de Ciências Biológicas (ICB II) da Universidade Federal de Goiás (UFG), localizados no município de Goiânia - GO, no período de março de 2006 a outubro de 2007.

Para a produção do complexo enzimático (CE), utilizou-se o fungo Humicola grisea var. thermoidea, isolado de compostagem na Universidade Federal de Viçosa (MG). Esse microrganismo tem a capacidade de produzir enzimas termoestáveis como celulases e xilanases.

$\mathrm{O}$ fungo $\mathrm{H}$. grisea foi cultivado em meio Ágar Aveia $(4,0 \%$ de farinha de aveia infantil Quaker, $1,5 \%$ de Ágar e água destilada) a $42^{\circ} \mathrm{C}$, durante quatro dias, e mantido posteriormente à temperatura ambiente por mais três dias. As placas de Petri, contendo o fungo, foram estocadas a 4 ${ }^{\circ} \mathrm{C}$.

A produção de enzimas hidrolíticas foi realizada em meio líquido, inoculando-se dez discos de cultura $(5 \mathrm{~mm})$, contendo esporos do fungo, por erlenmeyers de $1 \mathrm{~L}$ com $250 \mathrm{~mL}$ de meio de indução (forragem de milho: $5 \mathrm{~g} / \mathrm{L}$; extrato de levedura: $3 \mathrm{~g} / \mathrm{L}$; sulfato de amônia: 1,4 $\mathrm{g} / \mathrm{L} ; \mathrm{CaCl}_{2} \cdot 6 \mathrm{H}_{2} \mathrm{O}: 0,3 \mathrm{~g} / \mathrm{L}$; sulfato de magnésio: 0,3 g/L; elementos traços de $\mathrm{CuSO}_{4}$ e $\mathrm{FeSO}_{4}$ ). Os frascos foram incubados em agitador rotatório (Controlled Environment Incubator Shaker, Brunswick Scientific Co. Inc., U.S.A) à $42{ }^{\circ} \mathrm{C}$ e velocidade de $120 \mathrm{rpm}$. Após 96 horas de cultivo, o complexo enzimático foi filtrado e alíquotas foram coletadas e centrifugadas a $4000 \mathrm{rpm}$ por 10 minutos. O sobrenadante foi mantido a $4{ }^{\circ} \mathrm{C}$ para posterior realização de ensaios enzimáticos.

Atividade de celulase em papel de filtro (FPase) foi determinada utilizando-se uma tira de $1,0 \times 6,0 \mathrm{~cm}$ de papel de filtro Whatman $\mathrm{n}^{\circ} 1$ (50mg) como substrato. No tubo de ensaio contendo o papel, foram adicionados $150 \mu \mathrm{L}$ do extrato enzimático e $350 \mu \mathrm{L}$ de tampão citratofosfato $50 \mathrm{mmol}$. $\mathrm{L}^{-1}$. A mistura de reação foi incubada em banho-maria a $40{ }^{\circ} \mathrm{C}$ por 60 minutos. A reação foi interrompida com adição de $1 \mathrm{~mL}$ de ácido3,5-dinitrosalicílico (DNS). Posteriormente, 
as amostras foram fervidas por 10 minutos e esfriadas em banho de gelo.

A concentração de açúcar redutor liberado foi determinada espectrofotometricamente a 550 $\mathrm{nm}$ pelo método do DNS, utilizando-se glicose como padrão (MILLER, 1959). Uma unidade de atividade enzimática (U) foi definida como a quantidade de enzima necessária para formar um $\mu$ mol de açúcar redutor por minuto da reação.

A atividade xilanolítica foi determinada pela metodologia de açúcares redutores (DNS MILLER, 1959).

Para o ensaio enzimático utilizou-se $50 \mu \mathrm{L}$ do extrato enzimático, $100 \mu \mathrm{L}$ de xilana (oat spelts - sigma) e $350 \mu \mathrm{L}$ de tampão citrato fosfato 50 mmol. $\mathrm{L}^{-1}$. A mistura de reação foi incubada a $50^{\circ} \mathrm{C}$ por 30 minutos. Após esse período, foram adicionados $500 \mu \mathrm{L}$ de DNS à mistura, que foi incubada por 10 minutos em água fervente, com posterior adição de $1000 \mu \mathrm{L}$ de água destilada.

A concentração de açúcar redutor liberado foi determinada espectrofotometricamente a 540 nm, utilizando-se xilose como padrão. Uma unidade de atividade enzimática (U) foi definida como a quantidade de enzima necessária para formar um $\mu \mathrm{mol}$ de açúcar redutor por minuto da reação.

Determinou-se a atividade de $\beta$-glicosidase usando-se como substrato $\rho$-nitro-fenil- $\beta$ glicopiranosideo ( $\rho-\mathrm{NPG})$. A mistura de reação consistiu de $50 \mu \mathrm{L}$ do extrato enzimático, $350 \mu \mathrm{L}$ de tampão citrato fosfato 50 mmol.L $\mathrm{L}^{-1}$ e $100 \mu \mathrm{L}$ de substrato. $\mathrm{O}$ ensaio enzimático foi realizado em 10 minutos de incubação a $40^{\circ} \mathrm{C}$, sendo a reação interrompida com a adição de $1 \mathrm{~mL}$ de solução carbonato de sódio $(0,5 \mathrm{M})$. A quantidade de $\rho$ nitro-fenil liberada foi determinada espectrofotometricamente a $405 \mathrm{~nm}$. Uma unidade de atividade enzimática (U) foi definida como a quantidade de enzima necessária para formar um $\mu$ mol de $\rho$-nitro-fenil por minuto da reação.

Neste experimento, ensaios de $\mathrm{pH}$ ótimo foram realizados para verificar se as enzimas produzidas possuem atividade numa faixa de $\mathrm{pH}$ compatível com as condições do rúmen $(5,0-7,0)$.

As atividades das enzimas do complexo celulolítico foram avaliadas em tampão citrato fosfato $50 \mathrm{mmol} . \mathrm{L}^{-1}$, nos valores de $\mathrm{pH} 5,0 ; 5,5$; 6,$0 ; 6,5$ e 7,0. Os testes das enzimas celulase total; $\beta$-glicosidase e xilanase, nos diferentes $\mathrm{pHs}$, foram realizados conforme ensaio enzimático descrito acima.

Os ensaios da temperatura ótima foram também realizados para avaliar se as enzimas produzidas mantêm atividade na faixa de temperatura do rúmen $\left(39-42^{\circ} \mathrm{C}\right)$.

Os ensaios da temperatura ótima foram também realizados para avaliar se as enzimas produzidas mantêm atividade na faixa de temperatura do rúmen $\left(39-42^{\circ} \mathrm{C}\right)$. As atividades de celulase total, $\beta$-glicosidase e xilanase foram determinadas conforme método descrito no item ensaio enzimático, incubando-se amostras nas temperaturas de $30,40,50$ e $60^{\circ} \mathrm{C}$. Os testes foram realizados em tampão citrato fosfato 50 mmol. $\mathrm{L}^{-1}, \mathrm{pH}$ 6,5.

No ensaio de termoestabilidade, as enzimas celulase total, xilanase e $\beta$-glicosidase foram avaliadas nos tempos de 60, 120, 180 e 240 minutos, a $40^{\circ} \mathrm{C}$ e $\mathrm{pH}$ 6,5. Os testes foram realizados em tampão citrato fosfato $50 \mathrm{mmol} . \mathrm{L}^{-1}$.

No ensaio de digestibilidade verdadeira in vitro,foi utilizada metodologia descrita por TILLEY \& TERRY (1963), modificada para o fermentador ruminal DAISY II, seguindo-se metodologia apresentada no manual de utilização do equipamento (ANKOM ${ }^{\circledR}$ Technology) fornecido pelo fabricante. Nesse ensaio, avaliou-se a digestibilidade verdadeira in vitro da matéria seca(DIVMS) de forragem de milho, tratada com diferentes doses do complexo enzimático. A forragem de milho utilizada neste experimento era composta de 34,$6 ; 7,9$ e $49,1 \%$ de matéria seca, proteína bruta e fibra em detergente neutro, respectivamente.

Os tratamentos realizados foram: controle (10 mL de água esterilizada); nível 1 (2,5 mL do CE); nível 2 (5,0 mL do CE) e nível 3 (10 mL do CE). Os níveis de 2,5 e 5,0 foram completados para $10 \mathrm{~mL}$, com água esterilizada. As doses enzimáticas foram aplicadas por aspersão, de forma uniforme, em $17 \mathrm{~g}$ da forragem.

$\mathrm{O}$ experimento foi instalado em blocos ao acaso, com quatro repetições, em esquema de parcelas subdivididas $4 \times 4$. Os blocos (repetições) foram constituídos de quatro rúmens. As parcelas foram constituídas por forragem de milho tratada com quatro níveis de enzimas e as subparcelas por quatro momentos de avaliação (períodos de incubação). Os dados obtidos foram submetidos à análise de variância e as médias dos tratamentos foram comparadas pelo teste de Tukey a $5 \%$ de probabilidade, com auxílio do software R ( $R$ DEVELOPMENT CORE TEAM, 2010).

Por bloco, foram introduzidos 34 sacos de filtro-náilon F57 - ANKOM® ${ }^{\circledR}(32$ amostras 
tratadas, um branco e uma testemunha). As amostras foram incubadas por 12;24; 48 e 96 horas a $39^{\circ} \mathrm{C}$, em meio anaeróbio. Posteriormente, os sacos foram incubados em solução de detergente neutro para determinação da digestibilidade verdadeira in vitro.

$\mathrm{Na}$ coleta do líquido ruminal, foram utilizados dois novilhos mestiços (pardo suíço $\mathrm{x}$ Jersey e Jersey x girolando), com peso aproximado de 370 e $327 \mathrm{~kg}$, respectivamente, sendo os líquidos ruminais misturados para a condução do experimento. Os animais foram mantidos em piquetes e adaptados à dieta por 14 dias, antes da coleta do líquido e tiveram livre acesso à água e sal mineral. A dieta (base na MS), fornecida pela manhã, consistiu de $5 \mathrm{~kg}$ de feno de Tifton 85 e 2 $\mathrm{kg}$ de forragem de milho.
O cálculo da DVIVMS foi realizado pela seguinte fórmula $\left(\mathrm{ANKOM}^{\circledR}\right.$ technology): DVIVMS $\%=100-\left(\left(\mathrm{W}_{3}-\left(\mathrm{W}_{1} * \mathrm{C}_{1}\right)\right) * 100 / \mathrm{W}_{2}\right)$, em que:

$\mathrm{W}_{1}=$ peso da tara do saco filtro; $\mathrm{W}_{2}=$ peso das amostras; $\mathrm{W}_{3}=$ peso final do saco filtro depois da determinação in vitro e sequencial com solução de FDN; $\mathrm{C}_{1}=$ correção do saco de filtro em branco (peso final do saco após estufa/peso inicial do saco filtro).

\section{RESULTADOS E DISCUSSÃO}

Observou-se que as enzimas celulase e xilanase apresentaram maior atividade em $\mathrm{pH}$ 6,0. Em relação à $\beta$-glicosidase, a atividade da enzima foi maior em pH 6,5 (Figura 1).

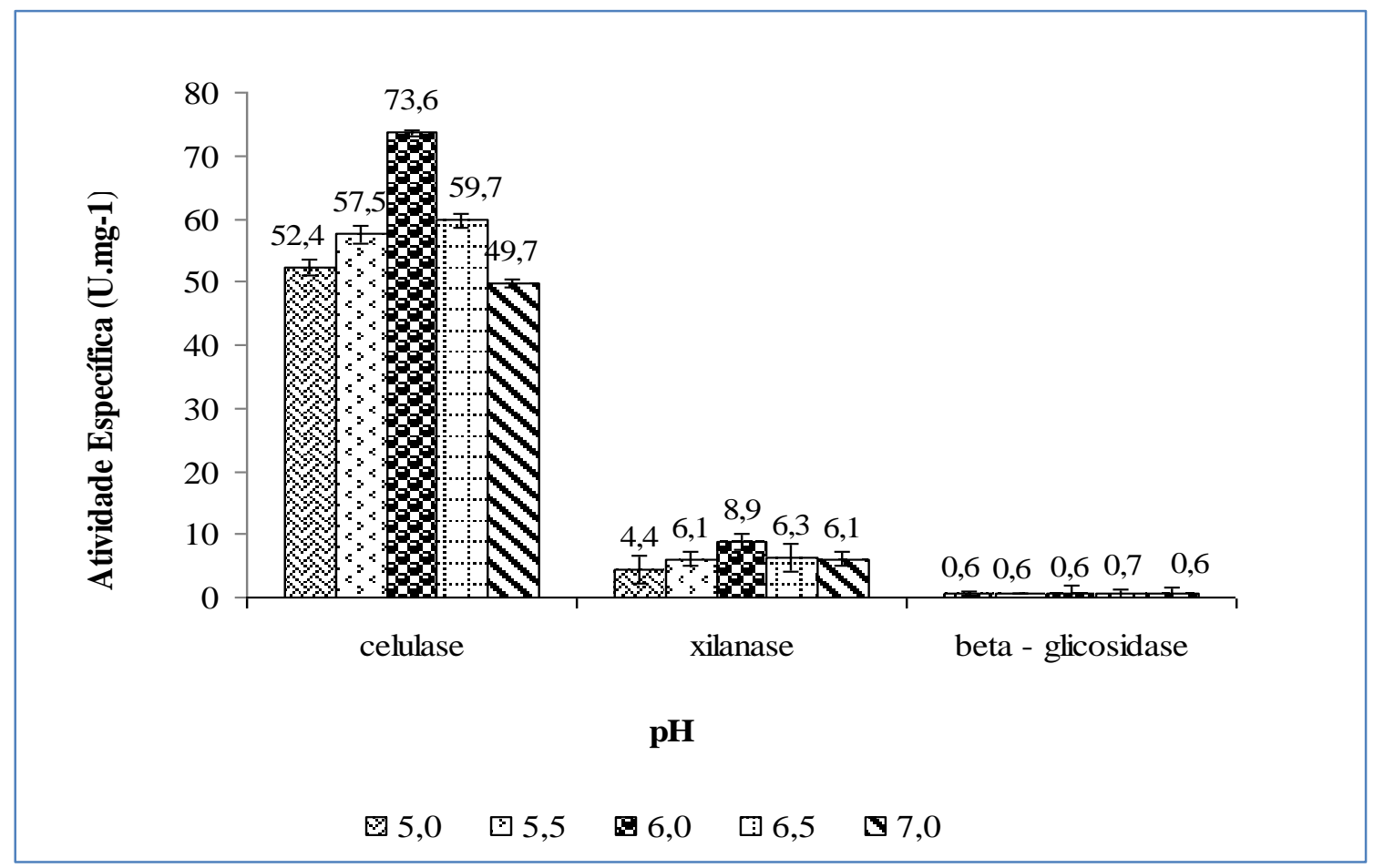

Figura 1. Influência do pH na atividade das enzimas do complexo enzimático.

$\mathrm{O}$ pH ótimo de celulases, xilanases e $\beta$ glicosidase é amplamente discutido na literatura e depende do microrganismo produtor.

Segundo MAHESHWARI et al. (2000), a atividade ótima de endo e exoglucanases de fungos termofílicos está entre 5,0 e 6,0. SILVA et al. (2005) verificaram valor ótimo de 5,0 para CMCase de $T$. aurantiacus. Resultados obtidos por EMTIAZI et al. (2000) mostram que celulase de Cellulomonas sp foi mais ativa em $\mathrm{pH} 6,0$, o que também foi obtido por LOWE et al. (1987) para celulase de Neocallimastix sp.

Segundo KULKARNI et al. (1999), xilanases produzidas por fungos são geralmente estáveis em intervalos amplos de $\mathrm{pH}(3,0-10,0)$, exibindo pH ótimo na faixa de 4,0 a 7,0.

LUCENA NETO \& FERREIRA FILHO (2004) mostraram que xilanase de $H$. grisea foi mais 
ativa em intervalos de $\mathrm{pH}$ de 4,5-6,5, o que corrobora o resultado obtido neste experimento.

KITPREECHAVANICH et al. (1984) e DUSTERHOFT et al. (1997) constataram que o pH ótimo de xilanases de $H$. lanunginosa e $H$. insolens foi 6,0 .

FERREIRA FILHO (1996) verificou maior atividade de $\beta$-glicosidase $H$. grisea em pH entre 4,0 e 4,5. LIN et al. (1999), caracterizando $\beta$-glicosidase de $T$. lanuginosus-SSBP, obtiveram 6,0 como $\mathrm{pH}$ ótimo. Boa parte das $\beta$-glicosidases fúngicas conhecidas apresentam pH ideal entre 4,0 e 6,5.

Observou-se, neste experimento, que as enzimas estudadas permaneceram estáveis na faixa de $\mathrm{pH}$ entre 5,0 e 7,0, sugerindo que essas proteínas teriam atividade nas condições de $\mathrm{pH}$ 5,0-7,0 do rúmen.

Enzimas para serem utilizadas na dieta de ruminantes devem ser estáveis a variações de temperatura ente 39 e $42^{\circ} \mathrm{C}$, uma vez que esta é a faixa de temperatura do rúmen, principal órgão de digestão dos ruminantes. A temperatura ótima encontrada para as enzimas celulase e xilanase produzidas foi de $50^{\circ} \mathrm{C}$. A enzima $\beta$-glicosidase manteve boa atividade na faixa de 50 a $60^{\circ} \mathrm{C}$ (Figura 2)

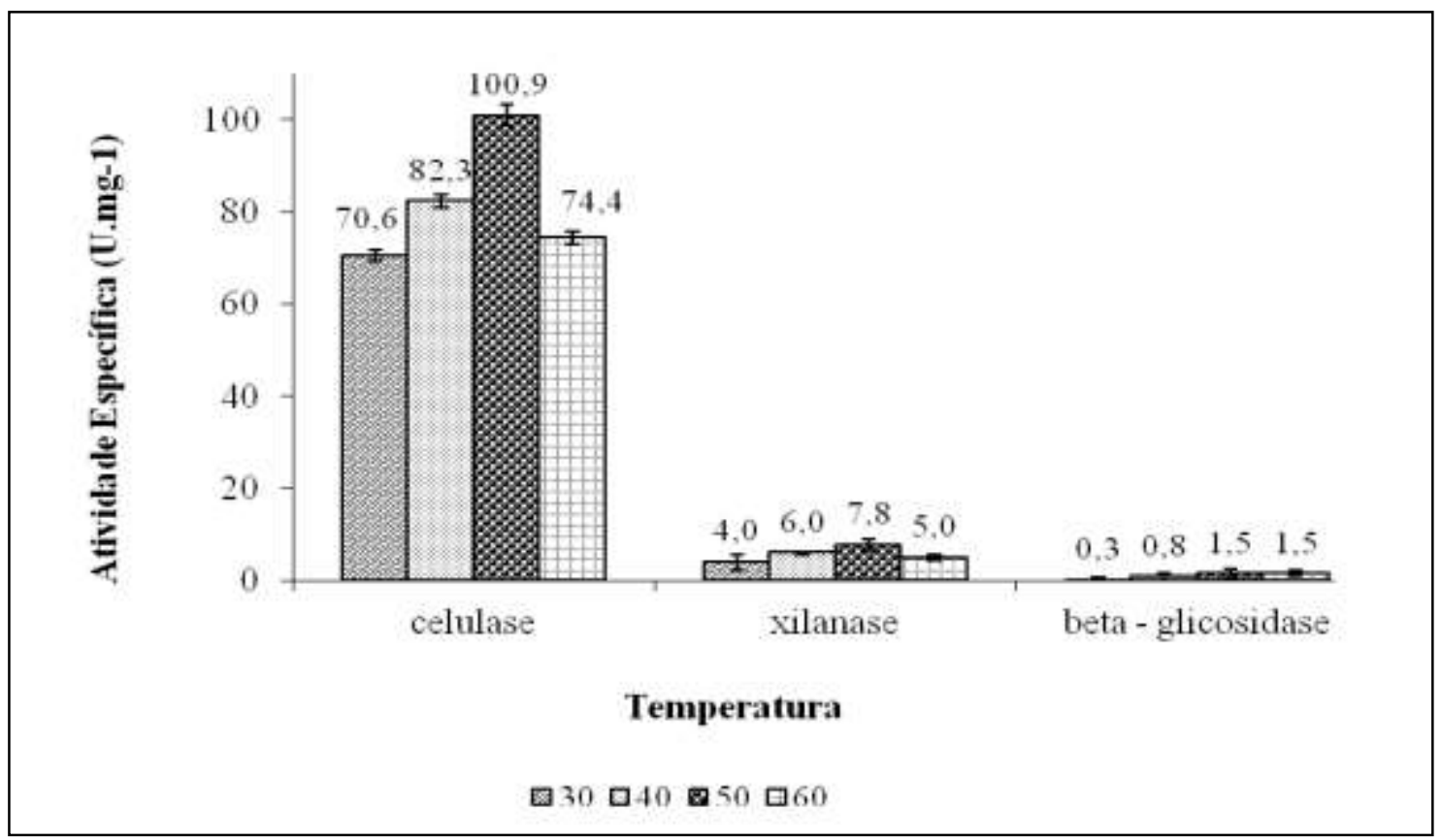

Figura 2. Influência da temperatura na atividade das enzimas do complexo enzimático.

Segundo MAHESHWARI et al. (2000), endoglucanases e exoglucanases de fungos termofílicos apresentam boa atividade em temperatura na faixa de 55 a $80^{\circ} \mathrm{C}$ e de 50 a $75^{\circ} \mathrm{C}$, respectivamente. Para $\beta-1,4$-exoglucanases e $\beta-1,4-$ endoglucanases de Humicola insolens, a temperatura ótima obtida foi de $50^{\circ} \mathrm{C}$, permanecendo estáveis a $65^{\circ} \mathrm{C}$, valores semelhantes ao encontrado para Thermoascus aurantiacus.

YOSHIOKA et al. (1982) verificaram que CMCase de $H$. grisea exibiu maior atividade na temperatura de $50^{\circ} \mathrm{C}$. Os pesquisadores LOWE et al. (1987) e EMTIAZI et al. (2000), em trabalhos realizados com Cellulomonas sp e Neocallimastix sp, respectivamente, registraram atividade ótima de celulase a $45^{\circ} \mathrm{C}$.

LUCENA-NETO \& FERREIRA FILHO,
(2004), trabalhando com xilanase de $H$. grisea, observaram maior atividade da enzima entre 55 e $60^{\circ}$ C. KITPREECHAVANICH et al. (1984) verificaram que xilanase de fungo $H$. lanunginosa foi mais ativa na faixa de 60 a $75^{\circ} \mathrm{C}$, com valor máximo de atividade a $65^{\circ} \mathrm{C}$, semelhante ao verificado para $H$. insolens (DUSTERHOFT et al., 1997) e xilanase de $H$ grisea (MONTI et al., 1991). Conforme KULKARNI et al. (1999), a temperatura ótima de xilanase de fungos varia entre 40 a $60^{\circ} \mathrm{C}$.

Pesquisa desenvolvida com os fungos $H$. grisea, $H$. lanunginosa e $H$. insolens mostrou que a $\beta$-glicosidase apresentou atividade ótima nas temperaturas de 50 a $60^{\circ} \mathrm{C}$ (MAHESHWARI et al., 2000). Esses resultados foram semelhantes aos obtidos por FERREIRA FILHO (1996), que estudou $\beta$-glicosidase de $H$. grisea var. thermoidea. LIN et 
al. (1999) observaram que $\beta$-glicosidasede Thermomyces lanuginosus-SSBP apresentou temperatura ótima de $65^{\circ} \mathrm{C}$.

Neste experimento, verificou-se que enzimas do $\mathrm{CE}$ do $H$. grisea demonstraram atividade específica na faixa de temperatura do rúmen, que, no entanto, é inferior à atividade apresentada nas temperaturas ótimas das enzimas.

Para serem utilizadas na alimentação animal, as enzimas devem apresentar ampla faixa de termoestabilidade para suportar a temperatura interna dos animais e variações de temperatura no processamento das rações. A termoestabilidade das enzimas varia consideravelmente em função da sua origem, sendo as enzimas fúngicas as que possuem maior estabilidade térmica (CASTRO \& MENDES, 2004).

Neste trabalho, observou-se que a celulase produzida permaneceu estável por 240 minutos, apresentando atividade relativa maior que $100 \%$. As enzimas xilanase e $\beta$-glicosidase mantiveram 99,2 e $88,2 \%$ de sua atividade com 240 minutos, respectivamente (Figura 3).

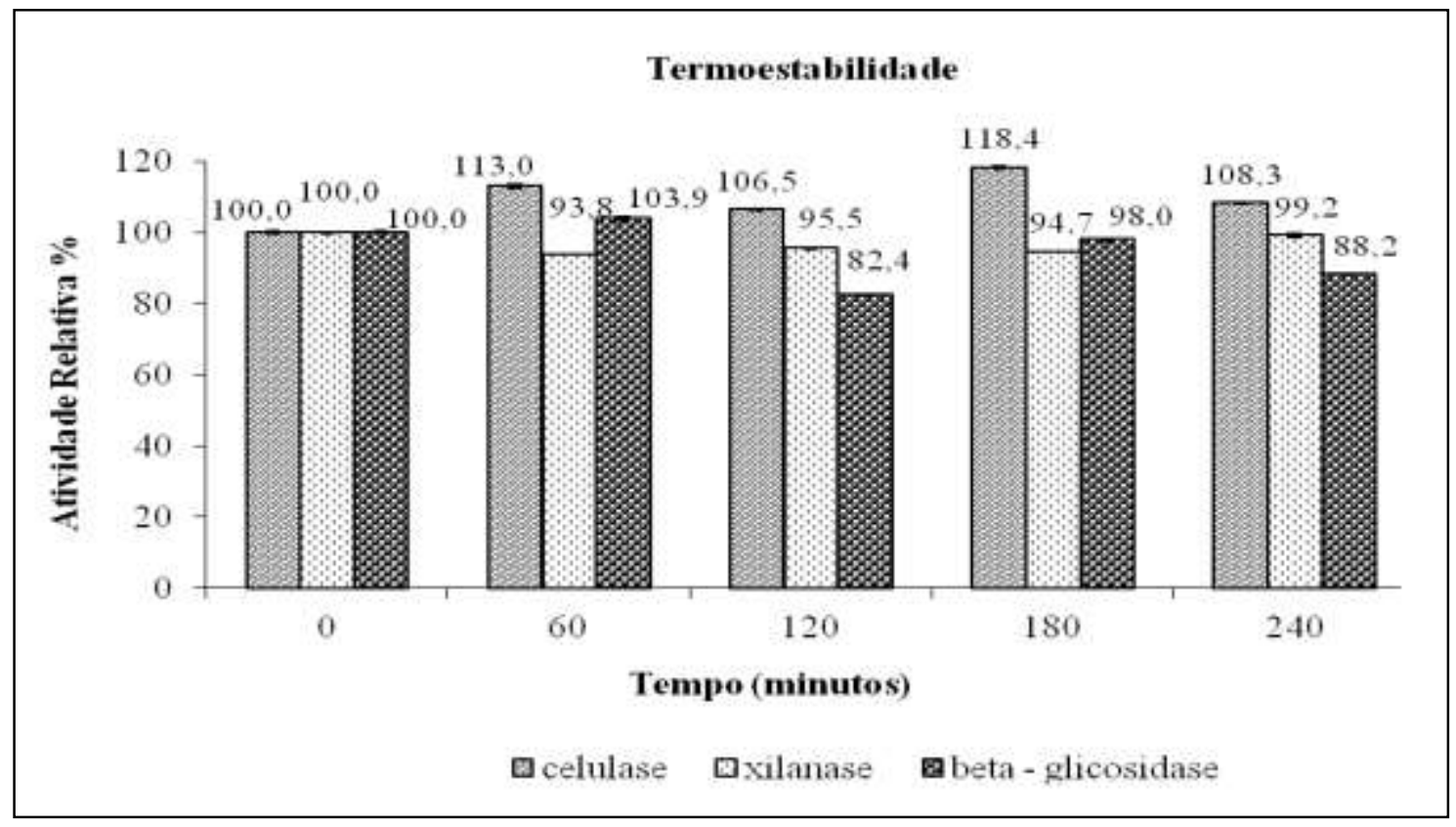

Figura 3. Estabilidade das enzimas do complexo enzimático em diferentes tempos.

OLIVEIRA et al. (2013) verificaram que endoglucanase produzida por $H$. grisea manteve $88 \%$ da sua atividade após 240 minutos de incubação a 50,60 e $70^{\circ} \mathrm{C}$. As temperaturas de 50 e $60^{\circ} \mathrm{C}$ aumentaram a atividade enzimática.

DAMASO et al. (2002) verificaram que xilanase produzida por $T$. lanuginosus permaneceu estável durante intervalo de tempo de 0 a 400 minutos, em $50{ }^{\circ} \mathrm{C}$. LUCENA-NETO \& FERREIRA FILHO (2004) constataram que xilanase de $H$. grisea var. thermoidea apresentou termoestabilidade a $60^{\circ}$ $\mathrm{C}$, com meia vida de aproximadamente 5,5 horas.

Xilanase purificada por MONTI et al. (1991) manteve boa estabilidade em temperaturas entre 40 e $60{ }^{\circ} \mathrm{C}$, apresentando meia-vida de 20 minutos a $60{ }^{\circ} \mathrm{C}$. REIS et al. (2001) avaliaram a termoestabilidade de quatro xilanases fúngicas e verificaram que três das enzimas mantiveram de 100 a $80 \%$ de sua atividade no intervalo de temperatura entre 50 a $70{ }^{\circ} \mathrm{C}$, enquanto a outra enzima manteve $40 \%$ de sua atividade a $50{ }^{\circ} \mathrm{C}$.

Em estudo desenvolvido por FERREIRA FILHO (1996), a enzima $\beta$-glicosidase produzida por H. grisea var. thermoidea foi termoestável a $60{ }^{\circ} \mathrm{C}$ por uma hora, apresentando meia vida de 15 minutos a $65{ }^{\circ} \mathrm{C}$. LIN et al. (1999) observaram que $\beta$ glicosidase do fungo $T$. lanuginosu manteve sua atividade total depois de 30 minutos de incubação a $50{ }^{\circ} \mathrm{C}$, mas foi inativada a $70^{\circ} \mathrm{C}$.

Os valores da DVIVMS da forragem de milho estão descritos na Tabela 1. Houve interação entre níveis enzimáticos e períodos de incubação no rúmen $(p<0,01)$. Verificou-se, em relação ao tratamento controle, que a adição de $2,5 \mathrm{~mL}$ de enzimas melhorou a DVIVMS em 4,88 e 6,87\%, com 12 e 48 horas de incubação ruminal, respectivamente. Para o tratamento de 5,0 mL, quando comparado ao controle, foram observados 
aumentos de 6,$66 ; 7,72$ e $5,42 \%$ sobre a digestibilidade, nos tempos de 12; 24 e 48 horas de incubação no rúmen, respectivamente. A aplicação de $10 \mathrm{~mL}$ de enzimas proporcionou melhoras na digestibilidade em 10,$58 ; 12,52 ; 9,05$ e $6,81 \%$, com $12 ; 24 ; 48$ e 96 horas de permanência da forragem no rúmen, respectivamente, em relação ao controle.

TABELA 1.Digestibilidade da forragem de milho em diferentes níveis de enzimas e quatro tempos de incubação no rúmen.

\begin{tabular}{lcccc}
\hline \multirow{2}{*}{$\begin{array}{l}\text { Nível de enzimas } \\
\text { (mL) }\end{array}$} & \multicolumn{4}{c}{ Período de incubação no rúmen (horas) } \\
\cline { 2 - 5 } Controle & $80,09 \mathrm{cB}$ & 24 & 48 & 96 \\
2,5 & $84,00 \mathrm{bB}$ & $86,50 \mathrm{cA}$ & $86,95 \mathrm{bA}$ & $90,05 \mathrm{bA}$ \\
5,0 & $85,42 \mathrm{abB}$ & $93,18 \mathrm{bA}$ & $92,92 \mathrm{aA}$ & $90,20 \mathrm{bA}$ \\
10,0 & $88,56 \mathrm{aB}$ & $97,33 \mathrm{aA}$ & $91,66 \mathrm{aA}$ & $91,98 \mathrm{bA}$ \\
\hline
\end{tabular}

Médias seguidas de letras diferentes, maiúscula na linha e minúscula na coluna, diferem ( $<<0,01)$ pelo teste Tukey. CV(subparcela) $\%=2,30 ; \mathrm{CV}$ (parcela) $\%=2,30$

Os aumentos da DVIVMS da forragem de milho são consequência da atividade hidrolítica das enzimas no substrato. Essa informação é consistente com a avaliação química do complexo enzimático utilizado no experimento, que revelou atividades de celulase e xilanase.

A adição de enzimas fibrolíticas às forragens, antes de sua ingestão, promove mudanças na estrutura dos alimentos, tornando-os mais susceptíveis à hidrólise ruminal (NSEREKO et al., 2000). De acordo com FONTES et al. (1995), as enzimas podem ser parcialmente protegidas da degradação ruminal, em decorrência da mudança de sua conformação. A alteração na estrutura da enzima é provocada por sua forte ligação com o substrato, quando da sua incorporação no alimento.

Segundo BEAUCHEMIN et al. (2003), existem evidências de que enzimas exógenas promovem a hidrólise de carboidratos solúveis durante a fase de pré-incubação ruminal. Sua aplicação direta no substrato favorece a formação de um complexo enzima-substrato bastante estável que aumenta a eficiência das enzimas exógenas no rúmen.

GIRALDO et al. (2007), aplicando duas celulases produzidas por Aspergillus niger e Trichoderma longibrachiatum, na dose de $30 \mathrm{U} / \mathrm{g}$ de substrato $(70 \%$ de feno de gramínea e $30 \%$ de concentrado), observaram maior desaparecimento da MS depois de 6 e 24 h, sem nenhum efeito após $48 \mathrm{~h}$ de incubação. LEWIS et al. (1996) não observaram aumento da DIVMS de feno de gramínea com 8; 16 e $24 \mathrm{~h}$ de incubação, quando da aplicação de enzimas fibrolíticas; entretanto, observaram aumento após 32, 40 e $96 \mathrm{~h}$.

CYSNEIROS et al. (2006) não verificaram efeitos de 5, 10 e $20 \mathrm{mg}$ de enzimas fibrolíticas por $\mathrm{kg}$ de matéria natural sobre o desaparecimento ruminal da MS da silagem de milho, em 6, 24 e $96 \mathrm{~h}$. YANG et al. (1999) verificaram que as curvas de digestibilidade ruminal da alfafa foram semelhantes para o tratamento controle e enzimático. $\mathrm{O}$ desaparecimento foi rápido durante as primeiras $12 \mathrm{~h}$ de incubação, com formação de platô próximo a 24 $\mathrm{h}$.

$$
\text { De acordo com DAWSON \& TRICARICO }
$$
(2007), uma série de estudos in vitro tem demonstrado que é possível usar preparações específicas de enzimas fibrolíticas para melhorar os processos associados à digestão do alimento no rúmen. A resposta é avaliada geralmente pelo aumento da taxa inicial de desaparecimento da matéria seca ou da taxa de desaparecimento da fibra em detergente neutro de forrageiras suplementadas com enzimas. Acredita-se que enzimas exógenas consigam tornar a fibra solúvel ou mais disponível ao ataque microbiano no rúmen. Segundo os mesmos autores, o período mais ativo para os efeitos de enzimas exógenas parece ser durante as primeiras 612 horas do processo digestivo. Na maioria dos casos, as enzimas fibrolíticas não exercem efeitos significativos sobre a digestão da fibra após períodos de incubação ruminal prolongados.

Ainda, algumas das variabilidades associadas ao uso de enzimas exógenas nas dietas de ruminantes estão relacionadas à suplementação com insuficiente ou excessiva quantidade de enzimas. As preparações de enzimas exógenas são muitas vezes utilizadas em baixas concentrações. Nessas concentrações, as enzimas parecem não contribuir para maior digestão da fibra no rúmen, mesmo que as condições do ambiente ruminal sejam ideais para 
suas atividades.

Estudos feitos por BEAUCHEMIN et al. (2003) demonstraram que o ótimo nível enzimático depende do substrato. Esses autores relataram diferentes taxas de aplicação de enzimas e diferentes respostas para feno de alfafa, silagem de milho, silagem de cevada e grãos de milho. Com feno de alfafa, observou-se redução no conteúdo da fibra em detergente neutro, mesmo com adição de um baixo nível enzimático, sem nenhuma alteração observada com altas taxas de aplicação. Altas quantidades de enzimas ligadas ao substrato podem restringir a ligação dos microrganismos do rúmen ao alimento limitando sua digestibilidade (BEAUCHEMIN et al., 2003).

Enzimas fibrolíticas estão relacionadas com sua capacidade de melhorar a degradação inicial dos carboidratos estruturais das plantas e complementar as atividades enzimáticas associadas aos microorganismos ruminais. É provável que enzimas exógenas ajam no rúmen logo após a ingestão do alimento e durante um período curto de tempo, antes da colonização bacteriana do alimento e início da digestão. Como resultado, enzimas fibrolíticas exógenas podem complementar as atividades enzimáticas dos microorganismos no rúmen e permitir maior digestão de substratos durante as fases preliminares críticas da digestão. Os efeitos globais da suplementação com enzimas podem resultar de sua capacidade de expor os substratos lentamente degradados ao ataque microbiano (DAWSON \& TRICARICO, 2007).

\section{CONCLUSÕES}

O fungo Humicolagrisea var. thermoidea é um produtor de enzimas fibrolíticas de interesse na alimentação de ruminantes. As enzimas celulase total, xilanase e $\beta$-glicosidase apresentaram atividades na faixa de temperatura e $\mathrm{pH}$ observados no rúmen. As enzimas, nos três níveis testados, aumentaram a DVIVMS da forragem de milho, mas não exerceram efeitos significativos sobre a digestão, após períodos prolongados de incubação ruminal.

\section{REFERÊNCIAS}

ACAMOVIC, T.; MCCLEARY, B. Enzyme Special Series-Optimising the response. Feed Mix, v. 4, p. 14-19, 1996.

BEAUCHEMIN, K.A.; RODE, L.M.; SEWALT, J.H. Fibrolytic enzymes increase fiber digestibility and growth rate of steers fed dry forages. Canadian Journal of Animal Science, v.75, p.641-644, 1995.

\footnotetext{
BEAUCHEMIN, K.A.; COLOMBATTO, D.;
}

MORGAVI, P.D.; YANG, Z.W. Use of exogenous fibrolytic enzymes to improve feed utilization by ruminants. Journal of Animal Science, v. 81, suppl. 2, p. 37-47, 2003a.

CASTRO, H.F.; MENDES, A.A.; SANTOS C.J. Modificação de óleos e gorduras por biotransformação. Química Nova, v. 27, n. 1, 146-156, 2004.

COLOMBATTO, D.; MOULD, F.L., BHAT, M.K.; OWEN. Use of fibrolytic enzymes to improve the nutritive value of ruminant diets. A biochemical and in vitro rumen degradation assessment. Animal Feed Science and Technology, v. 107, p. 201-209, 2003.

CYSNEIROS, C.S.S.; FRANCO, G.L.; ULHOA, C. J.; DIOGO, J. M. S.; RAMOS, A.K.B. Efeito de enzimas fibrolíticas sobre a composição química da silagem de milho. Ciência Animal Brasileira, v. 7, n. 4, p. 339-348, 2006.

DAMASO, M. C.T.; ANDRADE, C.M.M. C.; JÚNIOR, P.N. Production and properties of the cellulase-free xylanase from Thermomyces lanuginosus ioc-4145. Brazilian Journal of Microbiology, v. 33, p. 333 - 338, 2002.

DAWSON, K.A.; TRICARICO, J.M. The use of exogenous fibrolytic enzymes to enhance microbial activities in the rumen and the performance of ruminant animals.

em:http://en.engormix.com/Articles/View.aspx?id=695.

Publicado em: 31 out. 2007.

DUSTERHOFT, E.M.; LINSSEN, V.A.J.M.; VORAGEN, A.G.J.; BELDMAN, G. Purification, characterization, and properties of two xylanases from Humicola insolens. Enzyme Microbial Technology. v.20, p. 437 - 445, 1997.

EMTIAZI, G.; NAHVI, I.; Multi-enzyme production by Cellulomonas sp. grown on wheat straw. Biomass and Bioenegry, v. 19, p. 31-37, 2000.

FERREIRA FILHO, E. X. Purification and characterization of a $\beta$-glucosidase from solid state cultures of Humicola grisea var. thermoidea. Canadian Journal Microbiology. v. 42, p. 1-5, 1996.

FONTES, C.M.; HALL, J.; HIRST, B.H.; HAZLEWOOD, G.P.; GILBERT, H.J.The resistance of cellulases and xylanases to proteolytic inactivation. Applied Microbiology and Biotechnology, v.43, p.5257, 1995.

GIRALDO, L.A.; TEJIDO, M.L.; RANILLA, J.M.; CARRO, M.D. Effects of exogenous cellulase supplementation on microbial growth and ruminal fermentation of a high-forage diet in rusitec fermenters. Journal Animal Science, v. 85, p. 1962-1970, 2007.

KITPREECHAVANICH, V.; HAYASHI, M.; NAGAI, S. Purification and properties of endo-1,4- $\beta$-xylanase from Humicola lanuginose. Journal Ferment. Technology, v.5, p. $415-420,1984$.

KULKARNI, NEETA; SHENDYE, ABHAY; RAO, 
MALA. Molecular and biotechnological aspects of xylanases. FEMS Microbiology Reviews, v. 23, p. 411456, 1999.

LEWIS, G.E.; HUNT, C.W.; SANCHEZ. Effect of directfed fibrolytic enzymes on the digestive characteristics of a forage-based diet fed to beef steers. Journal of Animal Science, v. 74, n. 12, p. 3020-3028, 1996.

LIN J.; NDLOVU, L. M.; SINGH, S.; PILLAY, B. Purification and biochemical characteristics of beta-Dxylanase from a thermophilic fungus, Thermomyces lanuginosus - SSBP. Biotechnology Applied Biochemistry, v. 30, p. 73- 79, 1999.

LOWE, S.E.; THEODOROU, M.K.; TRINCI, A.P.J.; Cellulases and xilanase of an aerobic rumen fungus grown on wheat straw, wheat straw holocellulose, cellulose, and xylan. Applied and Environmental Microbiology, v.53, n. 6 , p. $1216-1223,1987$.

LUCENA-NETO, A.D.S.; FERRERIA FILHO, E.X. Purification and characterization of a new xylanase from Humicola grisea var. thermoidea. Brazilian Journal of Microbiology, v. 35, p. 86 - 90, 2004.

MAHESHWARI, R.; BHARADWAJ, G.; BHAT, K.M. Thermophilic Fungi: Their Physiology and Enzymes. Microbiology and Molecular Biology Reviews, v. 64, n. 3, p. $461-488,2000$.

MARTINS, A.S.; VIEIRA, P.F.; BERCHIELLI, T.T.; PRADO, I.N.; MOLETTA, J.L. Consumo e digestibilidade aparente total em bovinos sob suplementação com enzimas fibrolíticas. Revista Brasileira de Zootecnia, v.35, p.2118-2124, 2006.

MILLER, G.H. Use of dinitrosalicylic acid reagent for determination of reducing sugar. Analytical Chemistry, v.31, p. 426-428, 1959.

MONTI, R.; TERENZI, H.F.; JORGE, J.A. Purification and properties of an extracellular xylanase from the thermophilic fungus Humicola grisea var. thermoidea. Canadian Journal of Microbiology, v, 37, p. 675 - 681, 1991.

NSEREKO, V.L.; MORGAVI, D.P.; RODE, L.M.; BEAUCHEMIN, K.A.; McALLISTER, T.A. Effects of fungal enzyme preparations on hydrolysis and subsequent degradation of alfalfa hay fiber by mixed rumen microorganisms in vitro. Animal Feed Science and
Technology, v. 88, p. 153-170, 2000.

OLIVEIRA, G.S.; ULHOA, C. J.; SILVEIRA, M. H. L.; ANDREAUS, J.; POÇAS-FONSECA, M. J.; FARIA, F. P. An alkaline thermostable recombinant Humicola grisea var. thermoidea cellobiohydrolase presents bifunctional (endo/exoglucanase) activity on cellulosic substrates. Journal of Applied Microbiology and Biotechnology, v. 29, p. 19-26, 2013.

R DEVELOPMENT CORE TEAM R: A language and environment for statistical computing. $\mathrm{R}$ Foundation for Statistical Computing, Vienna, Austria. ISBN 3-90005107-0, URL http://www.R-project.org, 2010.

REIS, T.F.C.; DIAS, F.M.V.; FONTES, C.M.G.A.; SOARES, M.C.; FERREIRA, L.M.A. Avaliação do potencial biotecnológico de xilanases de Clostridiumthermocellum e Cellvibrio mixtus: sua utilização na suplementação de dietas a base de trigo para frangos de carne. Revista Portuguesa De Ciências Veterinárias, 96: 125-134. 2001.

SILVA, R.D.; LAGO, E.S.; MERHEB, C.W.; MACCHIONE, M.M.; PARK, Y.K.; GOMES, E. Production of xylanase and CMCase on solid state fermentation in different residues by Thermoascus aurantiacus miehe. Brazilian Journal of Microbiology, v. 36, p. $235-241,2005$.

SCHINGOETHE, D.J.; STEGEMAN, G.A.; TREACHER, R.J. Response of lactanting dairy cows to a cellulase and xylanase enzyme mixture applied to forages at the time of feeding. Journal of Dairy Science, v. 82, n. 5, p. 996-1003, 1999.

TILLEY, J.M.A.; TERRY, R.A. A two stage technique for the in vitro digestion of forage crops. Journal British Grassland Society, v. 18, p. 104-111, 1963.

YANG, W.Z.; BEAUCHEMIN, K.A.; RODE, L.M. Effects of an enzyme feed additive on extent of digestion and milk production of lactating dairy cows. Journal of Dairy Science, v.82, p.391-403, 1999.

YOSHIOKA, H.; ANRAKU, S.I, HAYASHIDA, S. Production and purification of a novel type of CMCase from Humicola grisea var. thermoidea YH-78. Agricultural Biologic Chemistry, v. 46, p. $75-82$, 1982. 